\title{
Factors Associated with Splenomegaly amongst Patients with Sickle Cell Disease in Cameroon
}

\author{
Eposse Ekoube Charlotte1,2, Alima Yanda Anastasia Nicole ${ }^{3,4}$, Djike Puepi Yolande5, \\ Cheping Kouokam Line 3 , Mandeng Ma Linwa Edgar ${ }^{*}$, Françoise Ngnedjou Nwabufor Foute 6 , \\ Mbono Ritha², Epee Patricia², Wete Estelle², Hassanatou Iyawa',2, Koki Ndombo Paul Olivier ${ }^{7}$
}

\author{
${ }^{1}$ Sickle Cell Care Center, Laquintinie Hospital, Douala, Cameroon \\ ${ }^{2}$ Faculty of Medicine and Pharmaceutical Sciences, University of Douala, Douala, Cameroon \\ ${ }^{3}$ Higher Institute of Medical Technology, Yaoundé, Cameroon \\ ${ }^{4}$ Chantal BIYA Foundation Mother Child Center, Yaoundé, Cameroon \\ ${ }^{5}$ Faculty of Health Sciences, University of Buea, Buea, Cameroon \\ ${ }^{6}$ Cosendai Adventist University, Nanga Eboko, Cameroon \\ ${ }^{7}$ Faculty of Medicine and Biomedical Sciences, University of Yaoundé 1, Yaoundé, Cameroon \\ Email: eekoubec@yahoo.fr, anica_2001@yahoo.fr, linecheping@yahoo.fr,*macadamcity_2007@yahoo.fr, \\ nwabuforfrancoise@gmail.com, patangou@yahoo.fr,yolandep2000@yahoo.fr, patepebm1@gmail.com, \\ weteestelle@gmail.com,koki_paul@hotmail.com
}

How to cite this paper: Charlotte, E.E., Nicole, A.Y.A., Yolande, D.P., Line, C.K., Edgar, M.M.L., Foute, F.N.N., Ritha, M., Patricia, E., Estelle, W., Iyawa, H. and Olivier, K.N.P. (2022) Factors Associated With Splenomegaly amongst Patients with Sickle Cell Disease in Cameroon. Open Journal of Pediatrics, 12, 33-46.

https://doi.org/10.4236/ojped.2022.121005

Received: January 17, 2022

Accepted: February 11, 2022

Published: February 14, 2022

Copyright ( 2022 by author(s) and Scientific Research Publishing Inc. This work is licensed under the Creative Commons Attribution International License (CC BY 4.0).

http://creativecommons.org/licenses/by/4.0/ (c) (i) Open Access

\begin{abstract}
Introduction: Sickle cell disease is the most common hemoglobinopathy in the world. Sickle cells are quickly fixed and destroyed by the elements of the reticuloendothelial system mainly in the spleen. It leads to a palpable increase in the volume of the spleen called splenomegaly. Splenomegaly is the cause of multiple complications that are relatively frequent and potentially serious in sickle cell disease, such as splenic sequestration seizures, spleen rupture, hypersplenism and splenic abscesses. We aimed at determining the prevalence of splenomegaly and to study the associated factors in patients with sickle cell disease. Materials and Methods: This was an analytical cross-sectional study, conducted from 1 January to 30 April 2019, at the Mother and Child Center of the Chantal BIYA Foundation. Patients were grouped into two groups: patients with splenomegaly (PS1) and patients without splenomegaly (PS0). As soon as we obtained the informed consent of the parents, we examined the children and recorded socio-demographic data, disease history and followup, documented complications, and clinical findings; then we performed the Rapid Malaria Diagnostic Test. The statistical analyzes were carried out using SPSS20 (Statistical Package for Social Sciences) and Microsoft Excel 2010 software. Results: We examined 403 children with sickle cell disease and 142 had splenomegaly (35\%). Almost all of the study populations were homozygous SS. The Hackett 2 stage of splenomegaly was the most frequent (56.7\%).
\end{abstract}


The most common physical sign among PS1 was the presence of abdominal scarring (50.7\% vs. 19.4\%). PS1 had significantly lower levels of $\mathrm{Hb}$ (6.94 \pm 1.67 vs $7.62 \pm 1.43 \mathrm{p}=0.003)$ and platelets $(297.45 \pm 146.25$ vs $398.70 \pm$ $163.73 \mathrm{p}<0.001$ ) than patients without splenomegaly (PS0). However, the percentages of $\mathrm{HbF}(21.78 \pm 10.48$ vs $15.66 \pm 9.20 \mathrm{p}<0.001)$ and malaria infection $(74.6 \%$ vs $17.2 \%$ p $<0.001)$ were statistically higher among PS0. Logistic regression analysis determined that the factors associated with splenomegaly were: malaria, high fetal hemoglobin, low hemoglobin S, hepatomegaly, thrombocytopenia and use of non-steroidal anti-inflammatory drugs. Conclusion: Splenomegaly is a frequent physical sign of sickle cell disease in children and factors associated are malaria, high hemoglobin F, low hemoglobin S, hepatomegaly, thrombocytopenia and NSAID use.

\section{Keywords}

Sickle Cell Disease, Splenomegaly, Thalassemia, Malaria, Associated Factors

\section{Introduction}

Sickle cell disease is the most common hemoglobinopathy in the world [1]. Sickle cell disease is a hemoglobinopathy, secondary to the presence of abnormal hemoglobin ( $\mathrm{Hb})$, in the red blood cells, called $\mathrm{Hb} \mathrm{S}$. It is due to the replacement of glutamic acid by valine in position 6 on the beta chain of the globin protein [2]. The most widespread hereditary hemopathy in sub-Saharan Africa, it constitutes, according to the World Health Organization (WHO), a major public health problem [3] [4]. The prevalence of sickle cell trait (SA) in Central Africa is estimated at 25\% [5]. In Cameroon, in 2016, Sack et al. found a prevalence of hemoglobin S at 18.2\% in 703 newborns at Yaounde central hospital [6]. These HbS molecules, in a deoxygenated medium, have the property of polymerizing, thus deforming the red blood cells (RBCs) in the form of rigid sickles. Complications of sickle cell disease concern all organs, such as the spleen, which is affected early in the course of the disease [7]. In the medium term, progressive atrophy following multiple vaso-occlusive crises and infarction leads to splenectomy, the time to onset of which differs according to the authors; occurring in homozygous SS sickle cell sufferers at six years of age for some [8], while others find an increase in volume during the first decade of life [7]. In Africa, the prevalence of splenomegaly during sickle cell disease has been evaluated in Senegal at $17.5 \%$ [9]. This splenomegaly is more frequent during sickle cell disease with significant differences found between SC composite heterozygotes (32.3\%) and SS homozygotes (16.5\%) [8]. Plasmodium falciparum infection and the haplotype would play a major role in the persistence of splenomegaly in sickle cell patients from subSaharan Africa compared to African-American populations [9]. Splenomegaly gives rise to multiple relatively frequent and potentially serious complications in sickle cell disease, such as splenic sequestration crises, rupture of the spleen, hyper- 
splenism and splenic abscesses. Therefore, we wanted to determine the prevalence of splenomegaly and to study the associated factors in subjects suffering from sickle cell disease.

\section{Methods}

\subsection{Population, Location and Duration of Study}

Our source population consisted of subjects with sickle cell disease regularly followed up at the Mother and Child Center of the Chantal BIYA Foundation (CME/FCB). This center has a sickle cell care unit which includes five doctors, assisted by a team of seven nurses and a psychologist, all of whom are committed to putting their know-how at the service of patients. It has a capacity of twelve beds spread over four rooms for an average of 600 hospitalizations, 2000 outpatient consultations for sickle cell patients per year, in addition to preventive and awareness-raising activities. This service also oversees the association of parents of children with sickle cell disease at the said hospital, which has more than three hundred members. The sectors concerned by our study were: the sickle cell care unit, the emergency department, the outpatient clinics, the meetings of the association of parents and children with sickle cell disease. We recruited patients over a 4-month period from January $1{ }^{\text {to }}$ April 30, 2019

\subsection{Selection Criteria and Sampling}

We included in our study all patients: suffering from sickle cell disease, aged from six months to 15 years, having a hemoglobin electrophoresis less than 6 months old, regularly followed up. Was considered as a patient regularly followed-up: any patient having respected the control appointments, from the previous year until the moment of recruitment. All subjects who underwent a splenectomy, those who only had an electrophoresis made after blood transfusion less than 4 months ago, and those who did not sign the informed consent form were excluded from the study. We conducted an analytical cross-sectional study with both prospective and retrospective data collection. We conducted non-probability, consecutive, and non-exhaustive sampling. The minimum size of our sample was therefore 90 subjects according to a study carried out in Gabon which found a prevalence of splenomegaly at $37 \%$ in children with sickle cell disease [10].

\subsection{Data Collection Procedure and Tools}

Armed with our technical data sheet, we introduced ourselves to the parents of children, explained to them the study that we were conducting and invited them to authorize their child(ren) to take part. Once the informed consent form had been read and signed, we proceeded to the clinical examination of the child with sickle cell disease, under the benevolent presence of the parent. We consulted the medical files of the patients in search of additional information. When necessary, we made appointments and made phone calls to patients' parents. The palpation technique in search of a possible splenomegaly 
was as follows: the patient being in the supine position, hips flexed, we placed one hand flat by slightly depressing the wall at the level of the left iliac fossa and by having the patient breathe in. We went up with each inspiration until the edge of the hand slipped under the ribs. We started very low in the left iliac fossa to screen for large splenomegaly. All our data was collected using pre-tested data sheets.

\subsection{Data Management and Analytics}

The data was recorded on anonymous collection sheets (to ensure the confidentiality of the results). The data was entered into a CS Pro 6.3 (Census and Survey Processing System) input mask. Statistical analyzes were carried out with SPSS20 (Statistical Package for Social Sciences) and Microsoft Excel 2010 software. The completed questionnaires were well checked before the data was entered manually by us, in the machine. A second check was done by an independent individual to avoid any error. The results were presented as tables, figures and expressed as a percentage or in numbers.

\subsection{Ethical Considerations}

Before starting the recruitment we obtained the validation of the scientific committee of the Higher Institute of Medical Technology, then an ethical clearance of the Institutional Ethics Committee of Research for Human Health of the University of Douala (CEI-UD). Subsequently, we obtained research authorization from the director of the CME/FCB.

\section{Results}

At the end of our recruitment, we conducted our study on 201 children with sickle cell disease, among whom 67 were carriers of splenomegaly (PS1) and 134 not carriers of splenomegaly (PSO).

\subsection{Socio-Demographic Characteristics of the Study Population}

Of the 403 subjects with sickle cell disease, aged 6 months to 15 years; 142 were carriers of splenomegaly, i.e. a prevalence of $35.2 \%$ (142/403). The PS0 were mostly between 6 and 10 years old (40.3\%) with an average of 7.74 years. The female sex predominated in our sample (more marked among the PS1). This is shown in Table 1.

\subsection{Clinico-Biological Profile of the study Population}

Jaundice was statistically more common in PS0 than in PS1 $(41.8 \%$ vs $26.9 \% \mathrm{p}=$ 0.032). Concerning the physical signs, the most frequent was the presence of abdominal scarification scars more marked in PS0 than in PS1 with a significant difference; then come abdominal distension and hepatomegaly, which are statistically more frequent in PS1. The most represented stage in our study was Hackett stage 2 (56.7\%). 
Table 1. Demographic and clinical data of patients in the study.

\begin{tabular}{lccc}
\hline & PS1 (\%) & PS0 (\%) & Total (\%) \\
\hline DEMOGRAPHIC CHARACTERISTICS & & & \\
Age & & & \\
6 months - 6 years & $23(34.3)$ & $48(35.8)$ & $71(35.32)$ \\
6 - 10 years old & $27(40.3)$ & $43(32.1)$ & $70(34.82)$ \\
10 - 16 years old & $17(25.4)$ & $43(32.1)$ & $60(29.85)$ \\
Sex & & & \\
Male & $32(47.8)$ & $59(44.0)$ & $91(45.3)$ \\
Feminine & $35(52.2)$ & $75(56.0)$ & $110(54.7)$ \\
CLINICAL CHARACTERISTICS & & & \\
Jaundice & $18(26.9)$ & $56(41.8)$ & $74(36.8)$ \\
Abdominal distention & $26(38.8)$ & $4(3)$ & $30(14.9)$ \\
Scarifications & $34(50.7)$ & $26(19.4)$ & $60(29.9)$ \\
Hepatomegaly & $16(23.9)$ & $7(5.2)$ & $23(11.4)$ \\
Pallor & $49(73.1)$ & $112(83.6)$ & $161(80.1)$ \\
\hline
\end{tabular}

PS1: Patient with splenomegaly; PS0: Patient without splenomegaly.

The most frequent circumstance of initial diagnosis of sickle cell disease was the vaso-occlusive crisis type of hand-foot syndrome in the two groups of individuals i.e. carriers and non-carriers of splenomegaly ( $40.3 \%$ and $56.7 \%$ ), followed by severe anemia ( $26.9 \%$ and $17.2 \%)$. We consulted the vaccination record of each patient and recorded their vaccination status according to their age. The majority of patients did not have their vaccines up to date, regardless of their group.

In our sample, 33 PS1 have already been hospitalized or $49.25 \%$ against 78 PS0 or $58.21 \%$. There was no significant difference between the two groups in terms of mean consultations/year. PS0 are generally more prone to hospitalizations than PS1. The mean number of hospitalizations/year, which was $1.97 \pm 1.92$ in PS1, was statistically lower than that of PS0, which is $2.39 \pm 1.43$. Among PS1, the most common reasons for hospitalization were severe anemia (51.52\%). Vaso-occlusive crises (48.48\%) came second, followed by infections (39.39\%). However, the second group was more frequently admitted to hospital, in $52.56 \%$ of cases for vaso-occlusive crises, in $41.03 \%$ of cases for infections and in $38.46 \%$ of cases for severe anemia. The frequency of transfusions did not vary significantly between the two groups. There were no great differences in the frequency of occurrence of the various complications between the two groups.

Overall, PS0 were more medicated than PS1. The difference was significant for taking NSAIDs and folic acid. The hemoglobin electrophoresis profile of almost all of the individuals was of the SS type. Of 201 patients included, 199 were SS 
homozygotes (99\%), and 2 composite SC heterozygotes (1\%). The frequencies of splenomegaly according to patient hemoglobin electrophoresis were: SS homozygotes: 32 , 7\%; SC composite heterozygotes: $100 \%$;

The hemoglobin F level was on average equal to $21.78 \pm 10.48$ in PS1 and $15.66 \pm 9.20$ in PSO. This hemoglobin F level was statistically higher in PS1 than in PSO. In six patients, the presence of $\mathrm{HbA}$ was noted, apart from any context of recent transfusions. HbA had a similar level in PS1 and PSO.

Average hemoglobin and platelet counts were statistically higher in PS0 than in PS1. On the other hand, there were no significant differences in the mean number of white blood cells and reticulocytes between the two groups.

The vast majority of subjects in both groups of individuals slept under impregnated mosquito nets. We conducted a rapid diagnostic test for malaria to all our patients. The results obtained showed that the malaria infection was present in $74.6 \%$ of PS1 while only $17.2 \%$ of PS0 suffer from it. The mean frequency of blood transfusion since diagnosis was $2.261( \pm 2.781)$ in PS0 and $2567( \pm 2.781)$ in PS1, $\mathrm{p}=0.506$. The mean haemoglobin level on admission was lower in PS1 $(6.96 \pm 1.67)$ than in PS1 $(7.62 \pm 1.43), \mathrm{p}=0.003$ as shown in Table 2.

\subsection{Factors Associated with Splenomegaly}

The factors associated with splenomegaly are: malaria, hepatomegaly, number of platelets, taking nonsteroidal anti-inflammatory drugs, fraction of hemoglobin $\mathrm{F}$ and fraction of hemoglobin S. Indeed, malaria is 15.26 times, hepatomegaly is 6.06 times, hemoglobin F fraction above $10 \%$ and platelets below 400,000 is more likely to be found in patients with PS. This is shown in Table 3.

\section{Discussion}

The main objective of our study was to determine the prevalence of splenomegaly and to study the associated factors in subjects suffering from sickle cell disease at the Mother and Child Center of the Chantal BIYA Foundation.

The overall frequency of splenomegaly in our patients was $35.2 \%$. This result is similar to the $37.4 \%$ found by Thuilliez et al. in Gabon [11]. This prevalence is low, compared to that of $100 \%$, reported in Yaoundé in 2018 by Nama et al. [12]. This difference could be due to a selection bias, splenomegaly being a constant criterion of acute splenic sequestration and this was the study population in the study by Nama et al. In West Africa, Ranque et al. in 2007, two series of Nigerian

Table 2. Relationship between frequency of transfusion and haemoglobin level in the sample population.

\begin{tabular}{cccc}
\hline Factors & PS0 (SD) & PS1 (SD) & P-value \\
\hline $\begin{array}{c}\text { Mean number of transfusions since } \\
\text { Sickle Cell Disease diagnosis }\end{array}$ & $2.261( \pm 2.781)$ & $2.567( \pm 2.781)$ & 0.506 \\
Mean Haemoglobin level on admission $(\mathrm{g} / \mathrm{dL})$ & $7.62( \pm 1.43)$ & $6.94( \pm 1.67)$ & $\mathbf{0 . 0 0 3}$ \\
\hline
\end{tabular}

$\mathrm{SD}=$ Standard Deviation 
Table 3. Multivariate analysis of factors associated with splenomegaly.

\begin{tabular}{ccccc} 
& \multirow{2}{*}{$\begin{array}{c}\text { OR } \\
\text { adjusted }\end{array}$} & \multicolumn{2}{c}{$95 \%$ CI } & \multirow{2}{*}{ P-value } \\
\cline { 3 - 4 } & 0.209 & 0.060 & 0.729 & 0.014 \\
NSAIDs & 6.067 & 1.710 & 21.522 & 0.005 \\
Hepatomegaly & 15.626 & 6.608 & 36.951 & $<0.001$ \\
Malaria & 1.038 & 0.605 & 10.202 & 0.971 \\
Mean Hb level (g/dL) & 0.488 & 0.202 & 0.786 & 0.041 \\
Number of platelets & & & & \\
More than 400 & 2.266 & 1.632 & 8,120 & 0.039 \\
Hemoglobin fraction F & & & & \\
10; 10] & 0.111 & 0.019 & 0.646 & 0.015 \\
Hemoglobin S fraction & & & & \\
Over 90 & & & & \\
\hline
\end{tabular}

NSAIDS: Non-steroidal anti-inflammatory drugs.

patients with an average age of 21 and 24.7 years [5] found respective prevalences of $26.8 \%$ and $21 \%$. These values suggest a lower frequency than that observed in our study in pediatric patients. Moreover, in 2004, Awotua et al. during an ultrasound study conducted on 100 homozygous Nigerian children aged 6 to 15 years revealed splenomegaly in $27 \%$ of them [12]. This difference in prevalence is attributable to the older ages in the Nigeria series; older subjects have most often undergone autosplenectomy following multiple splenic infarctions. The same is true in the Middle East where the prevalence of splenomegaly is lower in series made up of subjects older than ours. Inati et al. in 2007, found splenomegaly in $28.9 \%$ of patients in a Lebanese series with an average age of 18 years [13]. The high prevalence of splenomegaly, $80 \%$, found by Russo-Mancusco et al. [14] in a series of 518 cases of heterozygous HbS -beta-thalassaemia in Italy, is linked to the preponderance of heterozygous forms in this region. Indeed, in Jamaica, GR Serjeant et al. [15] have carried out work on the comparison between sickle cell disease S Beta-0 Thalassemia and homozygous sickle cell disease. They found that persistence of splenomegaly is more common in patients in the first group. This persistence could come from less intravascular sickling in these heterozygotes, linked to the decrease in the average corpuscular concentration of hemoglobin S. In our series, splenomegaly was more common in SC composite heterozygous patients $(100 \%)$ than in homozygous $(32.1 \%)$. The frequency of splenomegaly in heterozygous SC patients in our series was higher than the prevalence of $68 \%$ in heterozygous SC patients reported by Adjenou et al. [16] in Togo, in 2006. The greater frequency of splenomegaly in heterozygous SC patients in our study could be explained by the rarity of this phenotype in Central Africa, resulting in a low representativeness of this group ( $1 \%$ of our population of study). 
Splenomegaly increased in frequency, from the age group of 6 months to 6 years $(34.3 \%)$, to that of 6 to 10 years $(40.3 \%)$ before decreasing from 10 to 16 years (25.4\%). These findings agree with the data of Diagne et al. [9] in 2010 in Senegal, for whom the frequency of splenomegaly increased from the age group of 0 - 5 years to that of $6-10$ years before decreasing thereafter. The same is true in India where Mukherjee et al. [17] found frequencies of $24.7 \%$ from 0 to 4 years old, $35.1 \%$ from 5 to 9 years old and $13.6 \%$ from 10 to 15 years old. These values are opposed to those of the literature where some authors [8] claim that complete splenic atrophy occurs in homozygous SS sickle cell disease at six years, following the congestive phase of the early years. Several hypotheses could explain this discrepancy. First, it is highly probable that many of the homozygous SS subjects in our study, carriers of splenomegaly, are actually compound heterozygotes. Note, for example, that the association SS-alpha thalassemia has the same tracing as homozygous sickle cell disease SS during conventional electrophoresis of hemoglobin at alkaline and acid $\mathrm{pH}$; however, almost all of our patients were diagnosed from the results of conventional electrophoresis of hemoglobin at alkaline $\mathrm{pH}$. Splenomegaly is more common in the association SS-alpha thalassemia than in homozygous sickle cell disease. Second, the existence of factors is likely to reduce the sickling of red blood cells and therefore the frequency of splenic infarctions in our study population. These include regular monitoring, educating patients to avoid factors that trigger sickling (cold, high altitudes, sustained and prolonged effort, etc.) and taking synthesis inducers of $\mathrm{Hb} \mathrm{F}$ such as hydroxyurea. Thirdly, the mean age of the inaugural consultations in our population was $2.9 \pm 2.49$ years. Inaugural consultations were an exclusion criterion in our study. This could have led to a selection bias, thus favoring the age group of 6 to 10 years. This hypothesis seems unlikely to us, because it is absent from the series of Diagne et al. [9] and Mukherjee et al. [17].

Clinically, PS1 and PS0 sickle cell patients had several points in common. These included pallor, poor vaccination status, frequency of annual consultations and transfusions, chronic complications of sickle cell disease and the actual adoption of certain therapeutic measures (hyperhydration, antibiotic therapy and taking hydroxyurea). This corroborates the findings of GR Serjeant et al. [15], for whom, apart from splenomegaly, all the other clinical parameters were similar in the two groups of the series studied. However, sickle cell disease is characterized by a great variability of clinical and biological expressions which depend on modulating genetic and environmental factors. The presence of abdominal scarification scars strongly represented in PS1 $(50.7 \%$ vs $19.4 \% \mathrm{p}<0.001)$ in our series is proof of this. In Cameroon, splenomegaly, commonly called "corner belle" meaning "at the edge of the abdomen", is a "disease" treated by traditional healers because many parents, out of ignorance, initially seek care from traditional healers. These healers perform abdominal scarifications whose purpose would be to extirpate the "bad blood" and to heal the "corner belle".

In our study, the analysis of clinical data showed a low frequency of va- 
so-occlusive crises in patients with splenomegaly compared to patients without splenomegaly (48.48\% vs $52.56 \%$ ). The same fact had been described in Nigerian children by Adekile [10]. Like them, we also noted a greater frequency of episodes of severe acute anemia in cases of splenomegaly. We found hepatomegaly in $23.9 \%$ of PS1 subjects. This percentage is low compared to the $71.9 \%$ found by Balci et al. [18] in 2008 in Turkey. This difference could be related to the technique used. Indeed, Balci et al. used ultrasounds while we palpated the abdomen of the patients. Most patients had splenomegaly at the second stage according to Hackett classification (Hackett stage 2). This represented $56.7 \%$ of all splenomegaly observed. This corroborates the results of Sangare et al. [19] where 87.5\% of patients had Hackett stage 2 splenomegaly. The splenomegaly seems more moderate in the association SS-alpha thalassemia.

In our series, PS1 were subject to more hospitalizations. The frequent reason for hospitalizations was severe anemia. On the other hand, the PSO had frequent hospitalizations for vaso-occlusive crises and infections. These results contradict those of Diagne et al. [9] in Senegal. In his series, there was no significant difference between the frequencies of hospitalizations. This difference in results would be due to a larger sample in Senegal (889 vs 201) and a longer study duration (14 years vs 4 months).

Biologically, the hematological profile of sickle cell disease associated with splenomegaly in our study shows average hemoglobin and platelet levels lower than those of sickle cell patients without splenomegaly. These results corroborate those found by Ranque et al. [5] in 2017 and Adeodu et al. [20]. The simultaneous presence of hemoglobin $\mathrm{S}$ and A outside any context of recent blood transfusions, with the percentages of $\mathrm{HbS}$ much higher than those of $\mathrm{HbA}$ in six of our patients, suggests the existence in our environment of other forms of sickle cell disease. It could be a composite $\beta S / \beta+$-thalassemia or $\beta S / \delta^{\circ} \beta$--thalassemia heterozygosity according to Zertal-Zidani et al. [21] or an association with an alpha triplication according to Steinberg et al. [22].

The higher hemoglobin $\mathrm{F}$ level in our patients who had splenomegaly is in favor of the role it would play in the persistence of splenomegaly during sickle cell disease [22]. This result was similar to that found by Diagne et al. in 2010 in Senegal [9]. Apart from the persistence of hemoglobin F, an associated alpha thalassemia trait would constitute a major etiological factor for the persistence of splenomegaly, as is the case in sickle cell patients in Congo [23] and India [17].

The rapid diagnostic test of malaria allowed us to find $74.6 \%$ of patients with splenomegaly (PS1) who had malaria. This value is higher than the $53 \%$ found by Mariam et al. [24] in Mali in 2009. This difference could be explained by the difference in the sensitivity of the tests chosen (TDR vs. thick film) and the study population. In Mali, Mariam et al. were interested in sickle cell patients in general, here the percentage of $74.6 \%$ of malaria infestation is observed in sickle cell patients with splenomegaly. In sub-Saharan Africa the persistence of splenomegaly is classic. In addition to the role of alpha-thalassemia and the persistence of hemoglobin F linked to the haplotype, malaria infestation would contribute to 
the increase in volume of the spleen in patients with sickle cell disease living in endemic areas [25] [26] [27]. Indeed, an overactive malarial splenomegaly is one of the main causes of massive splenomegaly in tropical regions. Its pathogenesis is related to an aberrant immunological response to repeated plasmodial infestations, resulting in an enlarged spleen sometimes associated with secondary hypersplenism [27].

Factors associated with splenomegaly were: malaria, hepatomegaly, number of platelets, use of nonsteroidal anti-inflammatory drugs, fraction of hemoglobin $\mathrm{F}$ and fraction of hemoglobin S.

Our study reports NSAIDS as a factor associated with decreased risk for splenomegaly $\mathrm{OR}=0.209(0.060-0.729)$. However, several drugs have been reported to cause splenomegaly through several mechanisms [28]. They may cause neutropenia and predispose to infections. In the fight against these infections, splenic enlargement may result [29]. Furthermore, drugs may cause hemolysis. Increased hemolysis will therefore recruit the spleen and splenomegaly will result [29]. Though not specifically with NSAIDS, several studies relative to druginduced hemolytic anemia (DIHA) in sickle cell patients [30] [31] [32] are available. Use of NSAIDs may reduce duration of sickle cell crisis by reducing pain, therefore halting the sickling cascade and may give an explanation for the findings in our study. Malaria however, is a well-known risk factor for splenomegaly. Malaria can cause an array of changes in the spleen ranging from mild enlargements to life-threatening splenomegaly [27] [33]. In our study, if a sickle cell patient had splenomegaly, he was 15 times more likely to also have malaria. This is in accordance with other studies. For example, Eleonore et al. [33] in Cameroon, 2020 , reported a prevalence of splenomegaly at $25 \%$ in SCD patients with malaria versus $17 \%$ without malaria. It will be expected that a patient with splenomegaly also has hepatomegaly as these are both parts of the reticuloendothelial system and react similarly to hemolysis, infections and hematological disorders [34]. In a study carried out in Nigeria, both hepatomegaly and splenomegaly occurs in 4 out of every 10 sickle cell patient which is similar to what we obtained in our study (3/10). Splenomegaly more likely associated with thrombocytopenia as abnormal sickled RBCs together with platelets are trapped in the splenic circulation and cause splenic enlargement [34] [35]. Our study reports a decreased association between platelets $>400,000$ cells/uL and splenomegaly. This has been reported similarly in literature. Generally, sickle cell patients with splenomegaly have associated thrombocytopenia especially in cases of acute sequestration crises [36]. High hemoglobin $\mathrm{F}$ ( $\mathrm{HbF}$ ) levels have been associated with persistent splenomegaly [37]. In our study, patients with $\mathrm{HbF}(0-10 \%)$ had twice increased probability of having splenomegaly. This may be a bias since $\mathrm{Hb}$ F has a protective role against sickling. Less sickling will imply less risk of autosplenectomy. In our sample, patients with autosplenectomy were not identified and could have been classified as PS0 erroneously. This brings bias because the spleen is not in the same state of function as for other patients [38]. Conversely a high level of $\mathrm{HbS}(>90 \%)$ was found to be less associated with splenomegaly. 
This result is biased because only $0.01 \%(2 / 206)$ patients had a genotype other than HbSS.

Splenomegaly is associated with several factors, investigated and non-investigated in the current study. It's a condition that is painful and sometimes becomes lifethreatening. More studies with more robust methodologies, longer follow-up, outcome determination and a wider sample need to be conducted for us to prevent and adequately manage sickle cell disease patients with splenomegaly.

\section{Conclusion}

Splenomegaly is common in $3 / 10$ patients with sickle cell disease. It is significantly associated with taking NSAIDs, hepatomegaly, malaria, platelets over 400.00, HBF fraction $<10 \%$ and HbS fraction $>90 \%$. Further studies are needed to confirm or invalidate these associated factors and to know the morbidity and mortality associated with splenomegaly in patients with sickle cell disease.

\section{Current State of Knowledge on the Subject}

- In Africa, the prevalence of splenomegaly in sickle cell disease was evaluated in Senegal at $17.5 \%$ by Diagne et al. Plasmodium falciparum infection and the haplotype would play a major role in the persistence of splenomegaly in sickle cell patients from sub-Saharan Africa compared to African-American populations.

- Splenomegaly gives rise to multiple relatively frequent and potentially serious complications in sickle cell disease, such as splenic sequestration crises, rupture of the spleen, hypersplenism and splenic abscesses.

- In Cameroon, data are almost non-existent. Therefore, we proposed to conduct this study, the general objective of which is to determine the prevalence of splenomegaly and to study the associated factors in subjects suffering from sickle cell disease at the Mother and Child Center of the Chantal Foundation. BIYA

\section{Contribution of Our Study to Knowledge}

- The prevalence of splenomegaly in our sample was $35.2 \%$.

- Patients with splenomegaly more frequently had scarification, abdominal distension, hepatomegaly and were less jaundiced.

- The factors associated with splenomegaly in patients with sickle cell disease were NSAIDs use, hepatomegaly, malaria, platelets over 400.00 cell/uL, HBF fraction $<10 \%$ and $\mathrm{HbS}$ fraction $>90 \%$.

\section{Authors' Contributions}

HD, HED, KOJ-PO and N-SM designed the study. HD and N-SM wrote the protocol. HD, HED, KOJ-PO and N-SM reviewed the protocol. HD collected and analyzed the data. N-SM supervised the study at every stage. HD and MMLE wrote the article. HD, CNS, MMLE, NCN' N-SM edited the article until submis- 
sion for publication. All authors have given their consent for the submission of the article.

\section{Acknowledgements}

Our deepest gratitude goes to the participants for their contribution.

\section{Conflicts of Interest}

The authors declare no conflicts of interest regarding the publication of this paper.

\section{References}

[1] Modell, B. (2008) Global Epidemiology of Haemoglobin Disorders and Derived Service Indicators. Bulletin of the World Health Organization, 86, 480-487. https://doi.org/10.2471/BLT.06.036673

[2] Hemoglobin S Molecule-What Causes Sickle Cell Anemia? World Mol. https://www.worldofmolecules.com/disease/hemoglobin S.htm

[3] Grosse, S.D., Odame, I., Atrash, H.K., Amendah, D.D., Piel, F.B. and Williams, T.N. (2011) Sickle Cell Disease in Africa. The American Journal of Preventive Medicine, 41, S398-S405. https://doi.org/10.1016/j.amepre.2011.09.013

[4] World Health Organisation. Sickle Cell Disease. https://www.afro.who.int/health-topics/sickle-cell-disease

[5] Ranque, B. (2017) The US3 Study: A First Step towards Large Scale Epidemiology for Sickle Cell Disease in Africa. Journal of Public Health and Emergency, 1, 13. https://doi.org/10.21037/jphe.2016.12.19

[6] Ngo Sack, F.F., Njangtang, D.M., et al. (2017) Prevalence of Sickle Cell Disease in Newborns in the Yaounde Central Hospital. The Journal of Medical Research, 3, 277-279. https://doi.org/10.31254/jmr.2017.3607

[7] Al-Salem, A.H. (2011) Splenic Complications of Sickle Cell Anemia and the Role of Splenectomy. ISRN Hematology, 2011, Article ID: 864257. https://doi.org/10.5402/2011/864257

[8] Dreyfus, B. and Breton-Gorius, J. (1992) L'hématologie de Bernard Dreyfus. Flammarion, Paris.

[9] Diagne, I., Coly, J.I., Deme-Ly, I. and Diag, N.R. (2008) Prevalence and Evolution of Splenomegaly in Children and Adolescents with Sickle Cell Disease in Senegal. British Medical Journal, 93, 297-299.

[10] Adekile, A.D., McKie, K.M., Adeodu, O.O., Sulzer, A.J., Liu, J.-S., McKie, V.C., et al. (1993) Spleen in Sickle Cell Anemia: Comparative Studies of Nigerian and U.S. Patients. American Journal of Hematology, 42, 316-321. https://doi.org/10.1002/ajh.2830420313

[11] Thuilliez, V., Ditsambou, V., Mba, J.R., Mba Meyo, S. and Kitengue, J. (1996) Aspects actuels de la drépanocytose chez l'enfant au Gabon. Archives de Pédiatrie, 3, 668-674. https://doi.org/10.1016/0929-693X(96)87087-4

[12] Nama Enyegue Philippe Hervé (2018) Séquestration splénique aiguë chez les drépanocytaires homozygotes SS hospitalisés au CME/FCB: Aspects épidémiologiques, cliniques, paracliniques et thérapeutiques.

[13] Inati, A., Jradi, O., Tarabay, H., Moallem, H., Rachkidi, Y., El Accaoui, R., et al. (2007) Sickle Cell Disease: The Lebanese Experience. International Journal of Laboratory 
Hematology, 29, 399-408. https://doi.org/10.1111/j.1751-553X.2007.00964.x

[14] Russo-Mancuso, G., Romeo, M.A., Guardabasso, V. and Schilirò, G. (1998) Survey of Sickle Cell Disease in Italy. Haematologica, 83, 875-881.

[15] Serjeant, G.R., Sommereux, A., Stevenson, M., Mason, K. and Serjeant, B.E. (1979) Comparison of Sickle Cell- $\beta$ Thalassaemia with Homozygous Sickle Cell Disease. British Journal of Haematology, 41, 83-93. https://doi.org/10.1111/j.1365-2141.1979.tb03684.x

[16] Adjenou, K.V., Agoda-Koussema, L.K., Djato, A., Holomashie, S., Hounsi, F., Attignon, A., et al. (2006) Echographie abdominale chez le drepanocytaire majeur. Journal de la Recherche Scientifique de I'Université de Lomé, 8, 1447.

https://www.ajol.info/index.php/jrsul/article/view/52067

[17] Mukherjee, M.B., Surve, R., Tamankar, A., Gangakhedkar, R.R., Ghosh, K., Lu, C.Y., et al. (1998) The Influence of Alpha-Thalassaemia on the Haematological \& Clinical Expression of Sickle Cell Disease in Western India. Indian Journal of Medical Research, 107, 178-181.

[18] Balci, A., Karazincir, S., Sangün, O., Gali, E., Daplan, T., Cingiz, C., et al. (2008) Prevalence of Abdominal Ultrasonographic Abnormalities in Patients with Sickle Cell Disease. Diagnostic and Interventional Radiology (Ankara, Turkey), 14, 133-137.

[19] Sangare, A., Sanogo, I., Meite, M., Segbena, Y., Toure, A.H., Elenga, J.P., et al. (1993) Profil clinique et évolutif de l'association drépanocytose homozygote-alpha thalassémie. Medecine d' Afrique Noire, 40, 741-745. http://www.santetropicale.com/Resume/124007.pdf

[20] Adeodu, O.O. and Adekile, A.D. (1990) Clinical and Laboratory Features Associated with Persistent Gross Splenomegaly in Nigerian Children with Sickle Cell Anaemia. Acta Paediatrica, 79, 686-690. https://doi.org/10.1111/j.1651-2227.1990.tb11536.x

[21] Zertal-Zidani, S., Ducrocq, R., Weil-Olivier, C., Elion, J. and Krishnamoorthy, R. (2001) A Novel $\delta \beta$ Fusion Gene Expresses Hemoglobin A (HbA) Not Hb Lepore: Senegalese $\delta 0 \beta+$ Thalassemia. Blood, 98, 1261-1263.

https://doi.org/10.1182/blood.V98.4.1261

[22] Steinberg, M.H. and Embury, S.H. (1986) Alpha-Thalassemia in Blacks: Genetic and Clinical Aspects and Interactions with the Sickle Hemoglobin Gene. Blood, 68, $985-$ 990. https://doi.org/10.1182/blood.V68.5.985.985

[23] Mouélé, R., Boukila, V., Fourcade, V., Feingold, J. and Galactéros, F. (1999) SickleCell Disease in Brazzaville, Congo: Genetical, Hematological, Biochemical and Clinical Aspects. Acta Haematologica, 101, 178-184. https://doi.org/10.1159/000040950

[24] Koreissi, M. (2009) Complications aigues de la drépanocytose dans le service de pédiatrie du CHU Gabriel Touré. Thèse de Médecine, Bamako.

http://www.keneya.net/fmpos/theses/2009/med/pdf/09M174.pdf

[25] Awotua-Efebo, O., Alikor, E.A. and Nkanginieme, K.E. (2004) Malaria Parasite Density and Splenic Status by Ultrasonography in Stable Sickle Cell Anaemia (HbSS) Children. Nigerian Journal of Medicine, 13, 40-43.

[26] Abjah, U.M. and Aken'Ova, Y.A. (2003) Levels of Malaria Specific Immunoglobulin G in Nigerian Sickle Cell Disease Patients with and without Splenomegaly. Nigerian Journal of Medicine, 12, 32-38.

[27] De Franceschi, L., Sada, S. andreoli, A., Angheben, A., Marocco, S. and Bisoffi, Z. (2005) Sickle Cell Disease and Hyperreactive Malarial Splenomegaly (HMS) in Young Immigrants from Africa. Blood, 106, 4415-4417.

https://doi.org/10.1182/blood-2005-08-3109 
[28] Petroianu, A. (2007) Drug-Induced Splenic Enlargement. Expert Opinion on Drug Safety, 6, 199-206. https://doi.org/10.1517/14740338.6.2.199

[29] Strom, B.L. (1993) Nonsteroidal Anti-Inflammatory Drugs and Neutropenia. Archives of Internal Medicine, 153, 2119-2124.

https://doi.org/10.1001/archinte.1993.00410180065007

[30] Khurana, M. and Raj, S.S. (2017) Drug-Induced Hemolytic Anemia: A Fatal Complication Further Under-Recognized in Sickle Cell Disease. Open Journal of Blood Diseases, 7, 79-85. https://doi.org/10.4236/ojbd.2017.73008

[31] Quillen, K., Lane, C., Hu, E., Pelton, S. and Bateman, S. (2008) Prevalence of Ceftriaxone-Induced Red Blood Cell Antibodies in Pediatric Patients with Sickle Cell Disease and Human Immunodeficiency Virus Infection. The Pediatric Infectious Disease Journal, 27, 357-358. https://doi.org/10.1097/INF.0b013e3181629a55

[32] Johnson, S.T., Fueger, J.T. and Gottschall, J.L. (2007) One Center's Experience: The Serology and Drugs Associated with Drug-Induced Immune Hemolytic Anemia-A New Paradigm. Transfusion (Paris), 47, 697-702.

https://doi.org/10.1111/j.1537-2995.2007.01173.x

[33] Eleonore, N.L.E., Cumber, S.N., Charlotte, E.E., Lucas, E.E., Edgar, M.M.L., Nkfusai, C.N., et al. (2020) Malaria in Patients with Sickle Cell Anaemia: Burden, Risk Factors and Outcome at the Laquintinie Hospital, Cameroon. BMC Infectious Diseases, 20, Article No. 40. https://doi.org/10.1186/s12879-019-4757-X

[34] Hall, J.E. and Hall, M.E. (2011) Chapter 34. Resistance of the Body to Infection I. Leukocytes, Granulocytes, the Monocyte-Macrophage System, and Inflammation. In: Guyton and Hall Textbook of Medical Physiology, Elsevier, Amsterdam, 433.

[35] Andriani, A., Latagliata, R., Anaclerico, B., Spadea, A., Rago, A., Di Veroli, A., et al. (2016) Spleen Enlargement Is a Risk Factor for Thrombosis in Essential Thrombocythemia: Evaluation on 1,297 Patients: Splenomegaly in Essential Thrombocythemia. American Journal of Hematology, 91, 318-321. https://doi.org/10.1002/ajh.24269

[36] Kane, I. and Nagalli, S. (2022) Splenic Sequestration Crisis. In: StatPearls, StatPearls Publishing, Treasure Island. http://www.ncbi.nlm.nih.gov/books/NBK553164

[37] Moll, S. and Orringer, E.P. (1996) Splenomegaly and Splenic Sequestration in an Adult with Sickle Cell Anemia. The American Journal of the Medical Sciences, 312, 299-302. https://doi.org/10.1097/00000441-199612000-00009

[38] Al-Salem, A.H., Al-Aithan, S., Bhamidipati, P., Al Jam'a, A. and Al Dabbous, I. (1998) Sonographic Assessment of Spleen Size in Saudi Patients with Sickle Cell Disease. Annals of Saudi Medicine, 18, 217-220. https://doi.org/10.5144/0256-4947.1998.217 